\title{
Formula Optimization of Rifampicin Dry Powder Inhalation with Chitosan-Xanthan Carrier Using Response Surface Methodology
}

\author{
Silvia Surini", Rahmadina Providya, Kurnia Sari Setio Putri \\ Laboratory of Pharmaceutics and Pharmaceutical Technology Development, Faculty of Pharmacy, Universitas Indonesia, Depok, 16424, Indonesia.
}

\begin{tabular}{|c|c|}
\hline ARTICLE INFO & ABSTRACT \\
\hline $\begin{array}{l}\text { Article history: } \\
\text { Received on: } 28 / 11 / 2017 \\
\text { Accepted on: } 11 / 02 / 2018 \\
\text { Available online: } 31 / 01 / 2019\end{array}$ & $\begin{array}{l}\text { This study was aimed to obtain an optimum formula of rifampicin dry powder inhalation (DPI) with chitosan-xanthan } \\
\text { (CX) as a carrier by spray drying method using response surface methodology (RSM). Fourteen experimental formulas } \\
\text { were designed statistically by Box Behnken method by varying three parameters namely concentration of CX solution, } \\
\text { rifampicin/CX ratio, and inlet temperature of the spray dryer. The entrapment efficiency (EE), particle size, and drug } \\
\text { release in pH } 7.4 \text { (pulmonary condition) and pH } 4.5 \text { (pulmonary macrophages condition) of the rifampicin DPI were }\end{array}$ \\
\hline $\begin{array}{l}\text { Key words: } \\
\text { Chitosan-xanthan, dry } \\
\text { powder inhalation, } \\
\text { rifampicin, response surface } \\
\text { methodology, spray drying. }\end{array}$ & $\begin{array}{l}\text { from those } 14 \text { formulas possessed EE of } 112.00-149.08 \% \text { and average particle sizes of } 0.599-5.506 \mu \mathrm{m} \text {. Rifampicin } \\
\text { release in phosphate buffer medium } \mathrm{pH} 7.4 \text { was } 6.54 \%-22.95 \% \text { and in } \mathrm{pH} 4.5 \text { was } 12.02-48.60 \% \text {. The Design } \\
\text { Expert predicted that the optimum formula would be obtained with a concentration of CX solution of } 0.5 \% \text {, a ratio of } \\
\text { rifampicin to CX } 1: 1 \text {, and inlet temperature of the spray dryer at } 143^{\circ} \mathrm{C} \text {. The optimized formula produced a rifampicin } \\
\text { DPI with EE of } 108.9 \% \text {, the particle size of } 1.177 \mu \mathrm{m} \text {, and the rifampicin release of } 14.49 \% \text { (at pH } 7.4 \text { ) and of } 37.97 \% \\
\text { (at } \mathrm{pH} 4.5 \text { ). }\end{array}$ \\
\hline
\end{tabular}

\section{INTRODUCTION}

Pulmonary drug delivery system is increasingly investigated due to its potential to deliver the drug directly into the lung to provide higher local effect and target specific cells in the lung (Park et al., 2013). Rifampicin administration for latent tuberculosis (TB latent) therapy through peroral route may cause many adverse effects (such as hepatotoxicity, indigestion, altered renal function, and others) (FDA. 2016). Moreover, high-frequency of rifampicin administration in such long periods of time can cause difficulties for patients to always adhere to the medication, causing intolerance or resistance by M. Tuberculosis (Park et al., 2013). Therefore, pulmonary delivery of rifampicin is considered as prospective strategy to reduce administration doses, minimize side effects, and improve the effectiveness of rifampicin therapy.

"Corresponding Author

Silvia Surini; Laboratory of Pharmaceutics and Pharmaceutical Technology Development, Faculty of Pharmacy, Universitas Indonesia, Depok, 16424, Indonesia.E-mail: silvia@farmasi.ui.ac.id
In pulmonary drug delivery systems, solid form (dry powder inhalation) offers advantages over liquid formulation such as solution or suspension, due to its physical and microbial stability (Zhou, 2013). Dry powder inhaler should possess particular characteristics to be delivered into the lower airway, including spherical shape and particle size of 1-5 $\mu \mathrm{m}$ (Hickey, 2004). For this purpose, spray-drying method offers the best approach to produce spherical shape powder with size of $1-5 \mu \mathrm{m}$ (Keshani, 2015).

In a dry powder preparation, a carrier excipient plays an essential role in delivering the drug into its target of pulmonary macrophages. The excipients should be non-toxic to the lungs, facilitate drug preparation and administration, promote consistent drug release, and protect the drug from degradation (Patel, 2015). It is known that rifampicin formulations with chitosan carriers may increase particle uptake by pulmonary macrophages (Park et al., 2013). Thus chitosan was selected as a drug carrier in latent TB therapy. Based on previous research (Putri, Sulistomo \& Surini, 2017), the combination of chitosan with xanthan gum can form a polyelectrolyte complex (Esteban and Severian, 2005; Hamman, 2010) which has a better swelling index at $\mathrm{pH} 5$ than 
the swelling index on a chitosan alone. Therefore, rifampicin dry powder prepared using polyelectrolyte complex chitosan and gum xanthan as a carrier was expected to exhibit better drug release in pulmonary macrophages.

During preparation of rifampicin dry powder by spray drying method, several factors influence the characterization of the powder (Bolton and Bon, 2010). Therefore, those factors need to be optimized to obtain the best formula. Optimization using response surface methodology (RSM) allows the formulator to estimate the exact system in the formulation process, as well as the method, can determine the optimum conditions significantly (Hussain, 1991). In this study, Box Behnken design was used to design fourteen formulas by varying three parameters: concentration of $\mathrm{CX}$ solution, rifampicin/CX ratio, and inlet temperature of the spray dryer. The entrapment efficiency (EE), particle size, and drug release in phosphate buffer medium $\mathrm{pH} 7.4$ (pulmonary condition) and medium $\mathrm{pH} 4.5$ (pulmonary macrophages condition) of the obtained dry powder were then characterized and analyzed by Design Expert software to find the best formula.

\section{MATERIALS AND METHODS}

\section{Materials}

Rifampicin was procured from Shenyang Antibiotic, China. Chitosan was obtained from Bio Chitosan, Indonesia; gum xanthan was purchased from Tongliao Huanghelong Bioengineering, China, and other chemical reagents.

\section{Preparation of chitosan-xanthan excipients}

Chitosan-xanthan excipients (CX) was prepared based on previous research (Stefaniak, 2011) conducted by ArginSoysal, Kofinas, and Lo, which has been modified, by mixing chitosan solution and xanthan gum solution (1: 1) at $\mathrm{pH}$ 4.3-4.5. After the reaction process was completed, the stirring process was continued for 24 hours. The obtained precipitation was then washed with deionized water five times and dried in the oven at $70^{\circ} \mathrm{C}$.

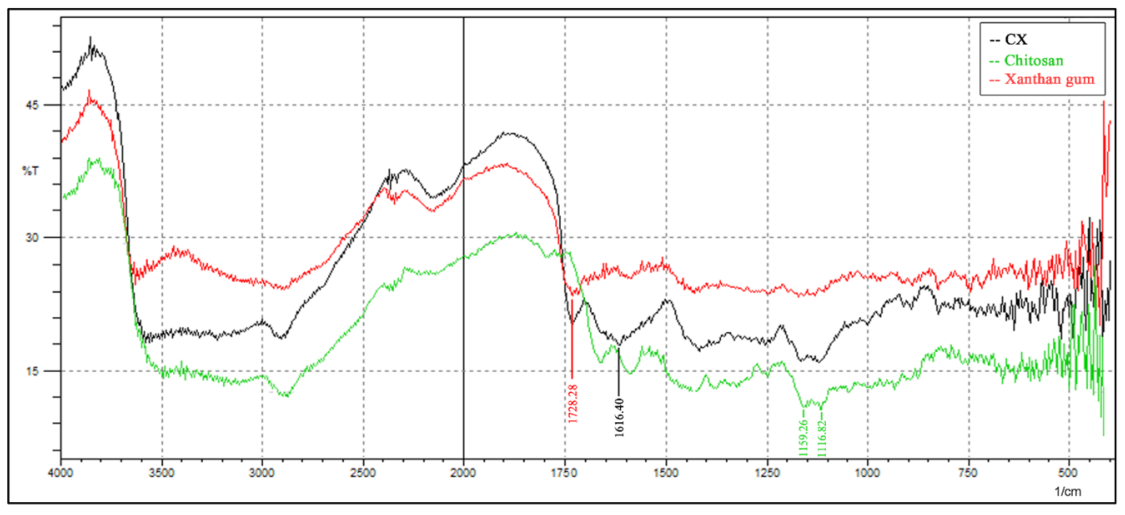

Fig. 1: Infrared spectrum of CX, chitosan, and gum xanthan.

\section{Characterization of $\mathbf{C X}$}

CX was characterized by its functional group and viscosity. The functional group of $\mathrm{CX}$ was analyzed using Fourier Transform Infra Red (FTIR-8400 S Shimadzu, Japan) at wave numbers 400 to $4000 \mathrm{~cm}^{-1}$ (Varshosaz et al., 2015). The IR spectrum obtained from the chitosan-xanthan polyelectrolyte complex was compared with each IR spectrum of chitosan and gum xanthan. The viscosity of $\mathrm{CX}$ was tested by viscometer Brookfield.

\section{Preparation of rifampicin dry powder inhalation}

The experimental design used in this research was BoxBehnken design, and 14 formulas were obtained from this model (Table 1). The CX was dissolved in the deionized water with concentration variations according to the formula, and rifampicin powder was dispersed into the CX solution. The solution was sprayed with a spray dryer (BUCHI Mini Spray Dryer B-290, German) with a flow rate of $25 \mathrm{~mL} / \mathrm{min}, 100 \%$ aspirator, and inlet temperature variation according to each formula. The obtained dry powder was collected.
Table 1: Parameters of rifampicin dry powder formulas from Box-Behnken design.

\begin{tabular}{cccc}
\hline \multirow{2}{*}{$\mathbf{F}$} & \multicolumn{3}{c}{ Parameters } \\
\cline { 2 - 4 } & CX concentration $(\% \mathbf{b} / \mathbf{v})$ & RIF:CX ratio & Inlet temp. $\left({ }^{\circ} \mathbf{C}\right)$ \\
\hline 1 & 0.1 & $1: 2$ & 120 \\
2 & 0.5 & $1: 2$ & 120 \\
3 & 0.1 & $1: 2$ & 160 \\
4 & 0.5 & $1: 2$ & 160 \\
5 & 0.1 & $1: 1$ & 140 \\
6 & 0.5 & $1: 1$ & 140 \\
7 & 0.1 & $1: 3$ & 140 \\
8 & 0.5 & $1: 3$ & 140 \\
9 & 0.3 & $1: 1$ & 120 \\
10 & 0.3 & $1: 1$ & 160 \\
11 & 0.3 & $1: 3$ & 120 \\
12 & 0.3 & $1: 3$ & 160 \\
13 & 0.3 & $1: 2$ & 140 \\
14 & 0.3 & $1: 2$ & 140 \\
\hline
\end{tabular}




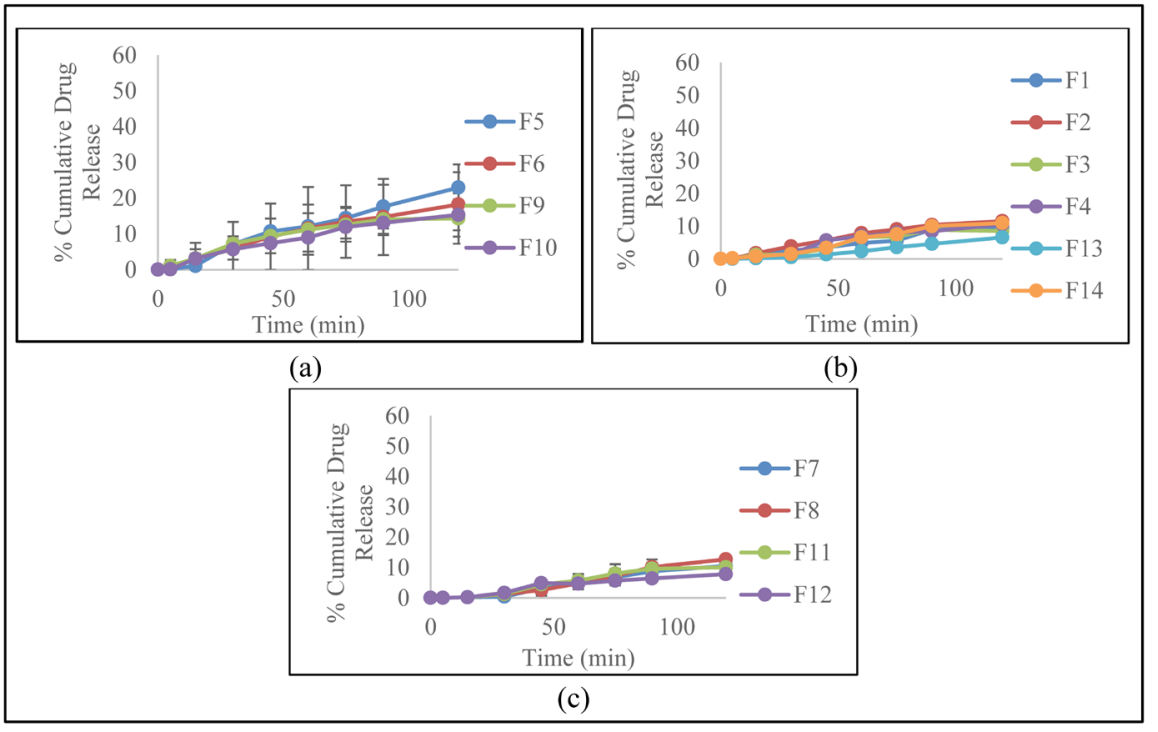

Fig. 2: Rifampicin release profile in medium phosphate buffer + SDS 0,05\% pH 7.4 with RIF:CX ratio (a) 1:1, (b) 1:2, (c) 1:3.

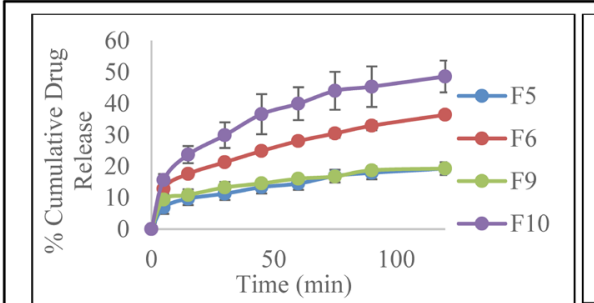

(a)

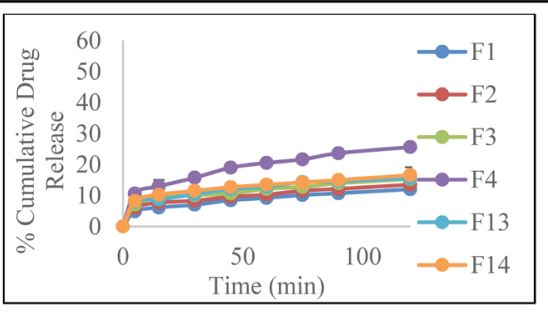

(b)

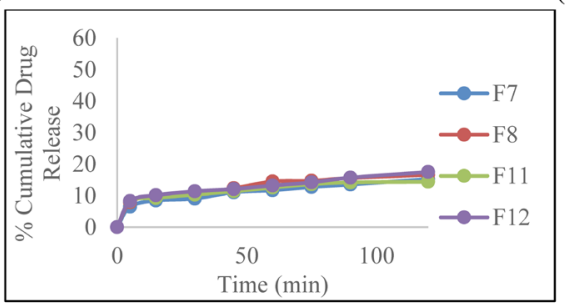

(c)

Fig. 3: Rifampicin release profile in medium potassium hydrogen phthalate pH 4.5 with RIF:CX ratio (a) 1:1, (b) 1:2, (c) 1:3.

\section{Particle size distribution}

Particle size distribution was determined using particle size analyzer with dynamic light scattering method (Chaudhary et al., 2013). A total of $1 \mathrm{mg}$ of powder was dissolved in 20 $\mathrm{mL}$ diethyl ether. The mixture was sonicated for 2 minutes and measured using Mastersizer 3000 MAZ 6240 (Malvern, UK).

\section{Entrapment Efficiency}

Dry powder equivalent to $25 \mathrm{mg}$ rifampicin was dissolved in methanol in a $25 \mathrm{~mL}$ flask. Two milliliters of solution was dissolved into the phosphate buffer $\mathrm{pH} 7.4$ in 100 $\mathrm{mL}$ measuring flask. The absorption was measured using UV-Vis spectrophotometer (UV-1800 Shimadzu, Japan) at maximum wavelength (British Pharmacopoeia, 2013). The level of rifampicin was determined by using a linear regression equation. Percentage of entrapment efficiency ( $\%$ EE) can be obtained using the formula:

$\mathrm{EE}(\%)=($ Actual concentration of rifampicin $) /($ Estimated concentration of rifampicin) $\times 100 \%$.

\section{Drug release}

The medium used in drug release test was pulmonary simulation fluid and pulmonary macrophage simulation fluid. Pulmonary simulation fluid $\mathrm{pH} 7.4$ was prepared from sodium phosphate buffer with $0.05 \%$ sodium dodecyl sulfate. The phagolysosomal lung macrophage simulation solution at $\mathrm{pH} 4.5$ was prepared using $0.02 \mathrm{M}$ potassium hydrogen phthalate with $\mathrm{pH}$ 4.5 (Stefaniak, 2011). 


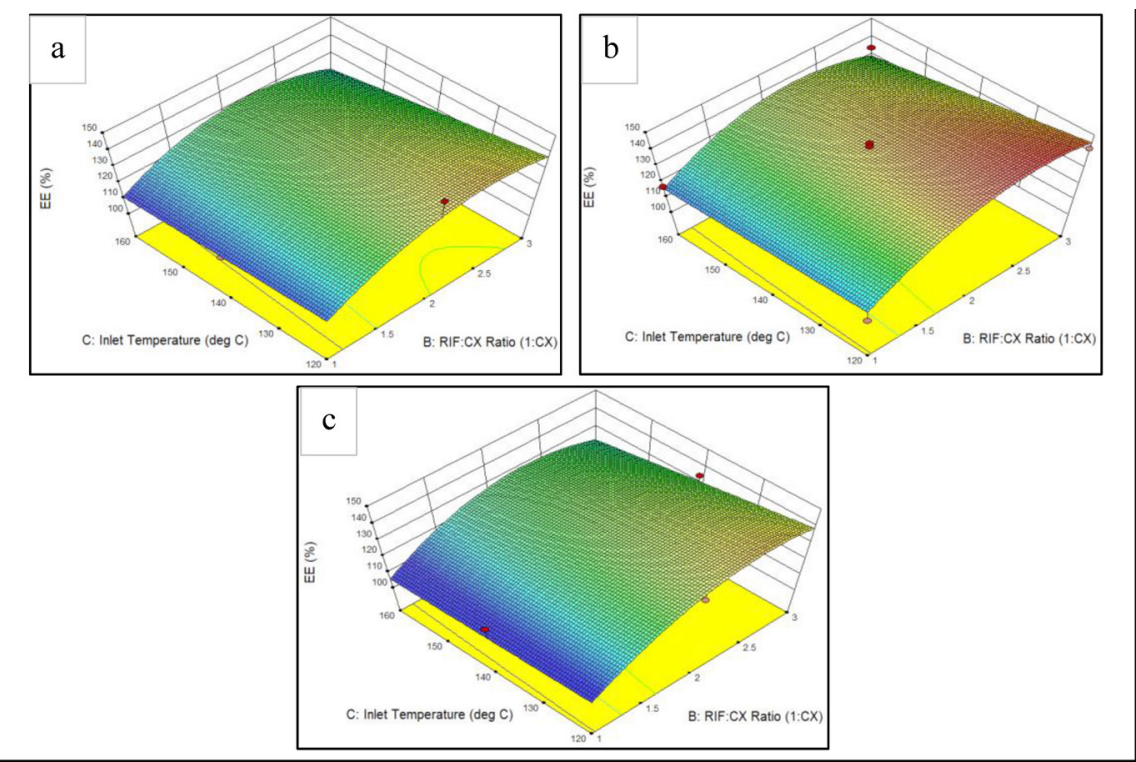

Fig. 4: Response surface of entrapment efficiency to RIF:CX ratio and inlet temperature in each CX concentration of (a) $0.1 \%$. (b) $0.3 \%$. (c) $0.5 \%$.

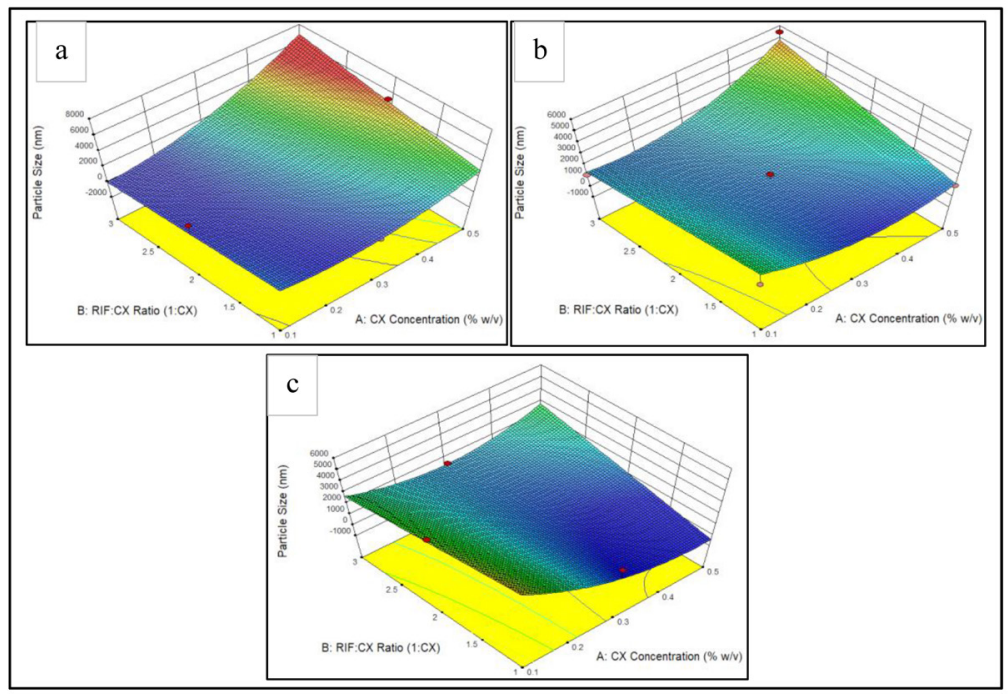

Fig. 5: Response surface of particle size to RIF:CX ratio and CX concentration in each inlet temperature of (a) $120^{\circ} \mathrm{C}$, (b) $140^{\circ} \mathrm{C}$, (c) $160^{\circ} \mathrm{C}$.

The $900 \mathrm{~mL}$ buffer solution was heated to $37^{\circ} \mathrm{C}$ and dissolution test was performed at $100 \mathrm{rpm}$. Each powder was put into the dissolution basket, and the drug release test was performed three times (triple). At 5, 15, 30, 45, 60, 75, 90 and 120 minutes, $6 \mathrm{~mL}$ of samples were taken out and filtered using $0.45 \mu \mathrm{m}$ Whatman filter (Son and McConville, 2009). The absorption of the sample solution was measured by a UV-Vis spectrophotometer at maximum wavelength.

\section{Optimization of formulas with surface response methodology}

The Box-Behnken design was applied to design the experiment. The minimum concentration was at position -1 , and the maximum concentration was at point 1 . Optimization of the formula in this research was using response surface methodology (RSM). The responses obtained from the fourteen formulas were then analyzed using Design Expert 9.0.6.2 software outlined in several stages: transforming the data, observing the effects of factors on response, selecting model equations, ANOVA analysis, diagnostics, display output in graph contour, and surface response (Myers et al., 2016).

\section{RESULTS}

\section{Characterization of chitosan-xanthan excipients}

Figure 1 showed that there was a new peak that appears on the $1616.41 \mathrm{~cm}^{-1}$ (amide group) wave number which was not present in the spectrum of chitosan and xanthan gum. In the spectrum of $\mathrm{CX}$, there were also functional groups owned by chitosan and xanthan gum. At wave number $1116 \mathrm{~cm}^{-1}$ and $1159 \mathrm{~cm}^{-1}$ and wave number $3100 \mathrm{~cm}^{-1}$ to $3500 \mathrm{~cm}^{-1}$ with the 
characteristic of peak width indicated existence of amine group $\left(-\mathrm{NH}_{3}\right)$ derived from chitosan. Also, the wave number 1728 $\mathrm{cm}^{-1}$ indicates the presence of carboxylic groups $(-\mathrm{COOH})$ and wave numbers $2400 \mathrm{~cm}^{-1}$ to $3400 \mathrm{~cm}^{-1}$ revealed the presence of carboxylic groups derived from xanthan gum.

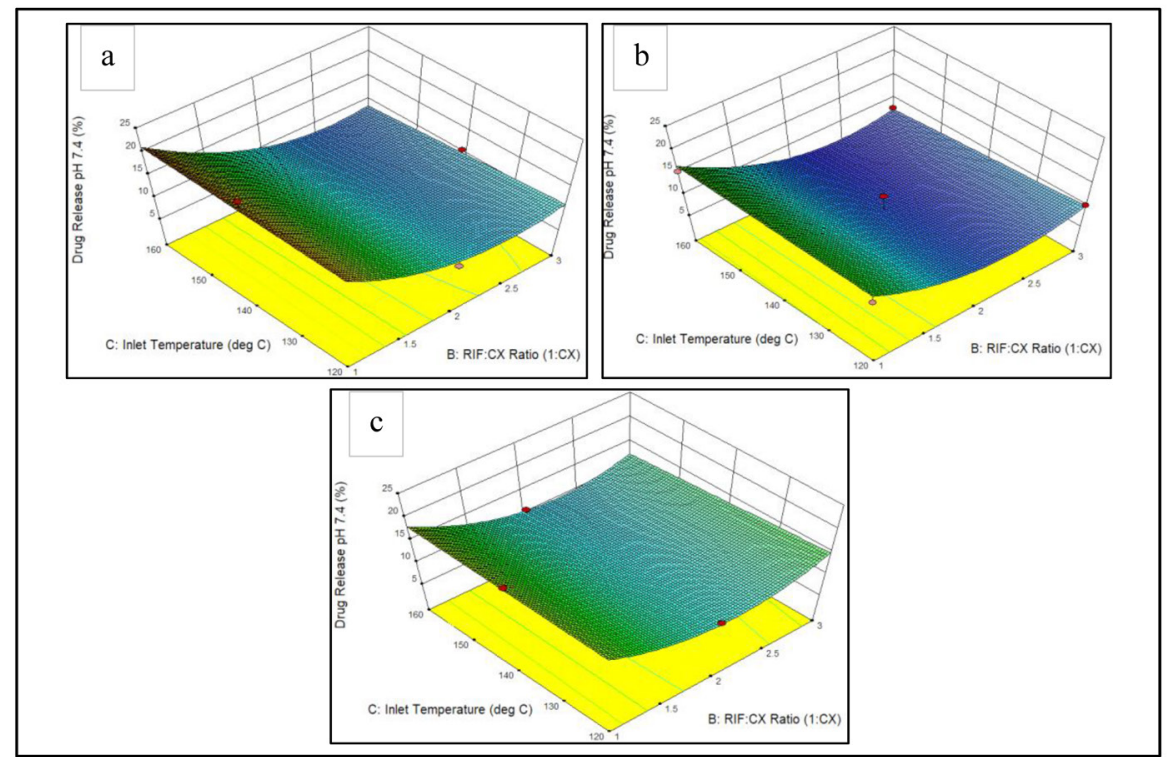

Fig. 6: Response surface of rifampicin release in medium pH 7.4 to RIF:CX ratio and inlet temperature in each CX concentration of (a) $0.1 \%$. (b) $0.3 \%$. (c) $0.5 \%$.

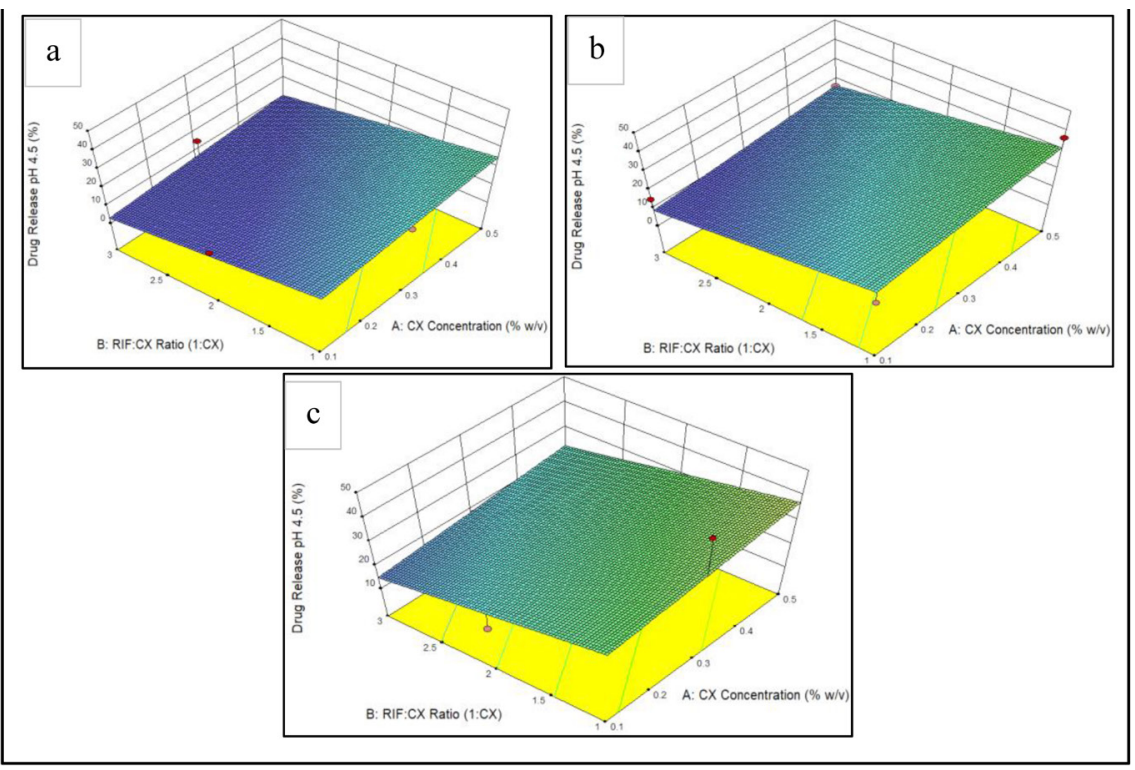

Fig. 7: Response surface of rifampicin release in medium $\mathrm{pH} 4.5$ to $\mathrm{CX}$ concentration and RIF:CX ratio in each inlet temperature of (a) $120^{\circ} \mathrm{C},(\mathrm{b}) 140^{\circ} \mathrm{C}$, (c) $160^{\circ} \mathrm{C}$.

\section{Particle size distribution}

The particle size of the dry powder was depicted in Table 2. The mean diameter ( $\mathrm{d}$ mean) of particle size of rifampicin inhalation powder has a size range of $0.60 \mu \mathrm{m}$ to $5.51 \mu \mathrm{m}$. There were two formulas (F4 and F9) that were not within the required particle size range for the inhalation powder $(1 \mu \mathrm{m}-5 \mu \mathrm{m})$. In the inhalation powder formulas with $0.3 \% \mathrm{CX}$ concentration variables had the lowest average particle size ranges of $0.64 \mu \mathrm{m}$ to 1.65 $\mu \mathrm{m}$, and in powders with $0.5 \% \mathrm{CX}$ concentration variables had the highest average particle size range, i.e., $0.60 \mu \mathrm{m}$ to $5.51 \mu \mathrm{m}$.

\section{Entrapment efficiency}

Table 2 also showed the entrapment efficiency results of the application of dry powder formulations. It can be seen that the entrapment efficiency of the fourteen formulas were more than $100 \%$, varied from $112.12 \%$ (F5) to $149.41 \%$ (F1). Based on the results obtained, it can be seen that the formula with the ratio RIF:CX 1:1 (F5, F6, F9, F10) had the average value of the entrapment efficiency closest to $100 \%$ that was $113.82 \% \pm 2.20 \%$. In the formula with the ratio RIF:CX 1:2 (F1, F2, F3, F4, F13, F14) had the highest average value of entrapment efficiency of 
$135.54 \% \pm 11.06 \%$. Besides, the formula for the ratio RIF:CX $133.99 \% \pm 6.66 \%$.

$1: 3 \mathrm{had}$ an average value of the high entrapment efficiency, i.e.,

Table 2: Parameters and responses of fourteen dry powder formulas.

\begin{tabular}{|c|c|c|c|c|c|c|c|}
\hline \multirow{3}{*}{$\mathbf{F}$} & \multicolumn{3}{|c|}{ Input variables } & \multicolumn{4}{|c|}{ Output parameters } \\
\hline & \multirow{2}{*}{$\mathrm{CX}$ concentration $(\% \mathrm{~b} / \mathrm{v})$} & \multirow{2}{*}{ RIF:CX ratio } & \multirow{2}{*}{ Inlet temp. $\left({ }^{\circ} \mathrm{C}\right)$} & \multirow{2}{*}{ EE\% } & \multirow{2}{*}{ Particle size $(\mathrm{d}$ mean $)(\mu \mathrm{m})$} & \multicolumn{2}{|c|}{ Rifampicin release in 24 hours } \\
\hline & & & & & & pH 7,4 & pH 4,5 \\
\hline 1 & 0.1 & $1: 2$ & 120 & $149.08 \pm 1.69$ & 1.740 & $9.53 \pm 0.87$ & $12.02 \pm 0.09$ \\
\hline 2 & 0.5 & $1: 2$ & 120 & $133.80 \pm 1.26$ & 5.19 & $11.52 \pm 1.92$ & $13.53 \pm 0.26$ \\
\hline 3 & 0.1 & $1: 2$ & 160 & $125.76 \pm 0.49$ & 3.90 & $8.49 \pm 2.90$ & $15.29 \pm 1.21$ \\
\hline 4 & 0.5 & $1: 2$ & 160 & $122.48 \pm 1.41$ & 0.60 & $10.55 \pm 0.78$ & $25.64 \pm 0.53$ \\
\hline 6 & 0.5 & $1: 1$ & 140 & $113.71 \pm 2.58$ & 1.09 & $18.23 \pm 9.02$ & $36.40 \pm 0.99$ \\
\hline 7 & 0.1 & $1: 3$ & 140 & $125.75 \pm 1.44$ & 1.11 & $10.53 \pm 1.83$ & $15.23 \pm 0.14$ \\
\hline 8 & 0.5 & $1: 3$ & 140 & $134.39 \pm 2.38$ & 5.51 & $12.65 \pm 1.04$ & $16.56 \pm 0.23$ \\
\hline 9 & 0.3 & $1: 1$ & 120 & $112.01 \pm 0.88$ & 0.64 & $14.30 \pm 7.06$ & $19.30 \pm 1.19$ \\
\hline 10 & 0.3 & $1: 1$ & 160 & $117.02 \pm 1.17$ & 1.55 & $15.33 \pm 4.34$ & $48.60 \pm 5.06$ \\
\hline 14 & 0.3 & $1: 2$ & 140 & $142.47 \pm 1.74$ & 0.86 & $10.93 \pm 0.76$ & $16.56 \pm 2.57$ \\
\hline
\end{tabular}

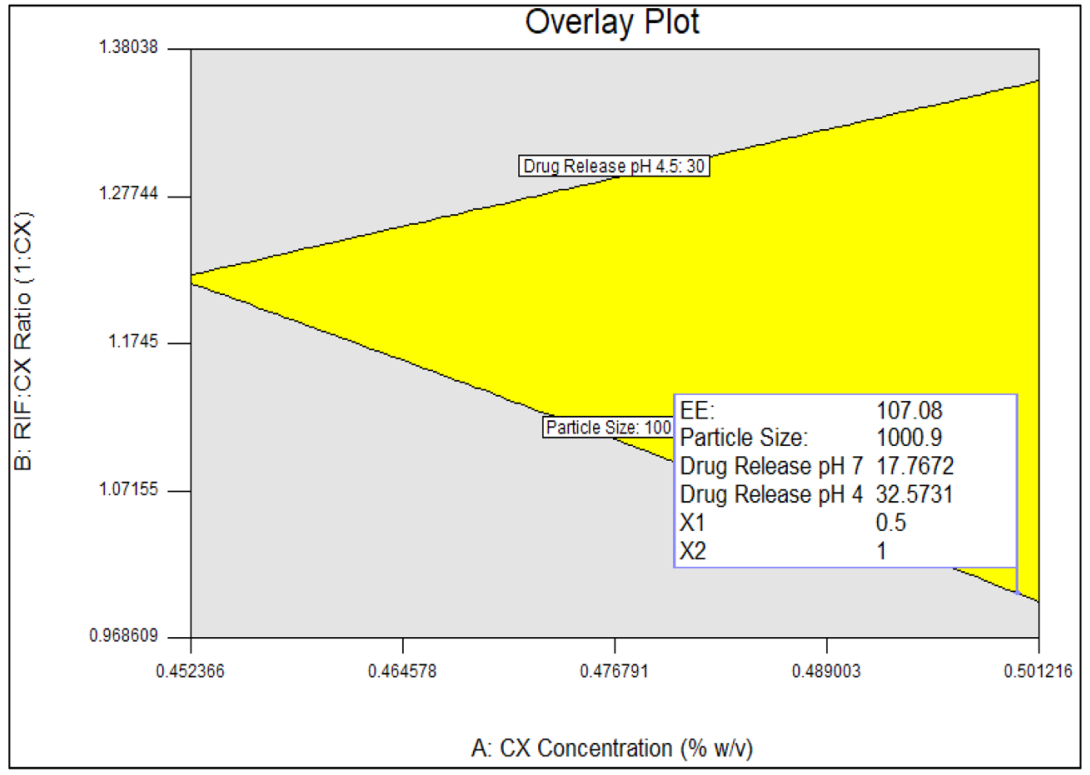

Fig. 8: Overlay plot graphic of optimization.

\section{Drug release}

Figure 2 and 3 show the release profile of dry powder rifampicin. At medium $\mathrm{pH} 7.4, \mathrm{CX}$ was able to control rifampicin release significantly. At a medium of $\mathrm{pH} 4.5$, all of the formulae released the drug immediately during first 5 minutes, in contrary to the release of rifampicin at a $\mathrm{pH}$ medium of 7.4 . This result suggested that the excipient has a role in retaining rifampicin release in a $\mathrm{pH}$ medium of 7.4 to 15 minutes. Rifampicin was released higher in the medium $\mathrm{pH} 4.5$, compared to its release in a $\mathrm{pH}$ medium of 7.4. The release of rifampicin in a medium $\mathrm{pH}$ of 7.4 for 2 hours has the highest value obtained in the formula with ratio of RIF:CX 1:1. Similarly, in a medium $\mathrm{pH}$ of 4.5 , the highest dissolution of rifampicin value for 2 hours is obtained in the formula with the ratio of RIF:CX 1:1.

\section{Formula optimization with response surface methodology}

The characterization results on fourteen formulas were input into Design Expert software, and the optimum formulas 
were analyzed with response surface methodology. Correlation between input and output parameters was investigated. The results obtained is displayed at Table 3.

Table 3: The correlation of the input variable and output response.

\begin{tabular}{cccc}
\hline Response & $\begin{array}{c}\text { CX } \\
\text { Concentration }\end{array}$ & $\begin{array}{c}\text { Inlet } \\
\text { temperature }\end{array}$ & RIF:CX ratio \\
\hline Entrapment efficiency & -0.067 & -0.299 & 0.631 \\
Particle size & 0.233 & -0.081 & 0.262 \\
Rifampicin release in $\mathrm{pH} 7.4$ & 0.032 & -0.072 & -0.664 \\
Rifampicin release in $\mathrm{pH} 4.5$ & 0.309 & 0.458 & -0.557 \\
\hline
\end{tabular}

*correlation value $>0.5$ is considered as strong correlation

In the data analysis, model of response surface methodology (RSM), such as linear, 2FI, quadratic, and cubic model, were evaluated. The model of polynomial equations for each response is selected based on the equations recommended by the program. The equation model is then modified so that it was significant to use. The Table 4 shows the selected model equations in each response.

The response variables were optimized based on the goal parameter specified as in Table 5. The parameters were combined, then the optimum region was obtained. The optimum point was shown in Figure 8.
Table 4: Model equations in each response.

\begin{tabular}{cc}
\hline Response & Model \\
\hline Entrapment efficiency & Quadratic \\
Particle size & Quadratic \\
Rifampicin release in $\mathrm{pH} 7.4$ & Quadratic \\
Rifampicin release in $\mathrm{pH} 4.5$ & Linear \\
\hline
\end{tabular}

Table 5: Goals parameters in each response.

\begin{tabular}{cccc}
\hline Response & Lower limit & Upper limit & Goals \\
\hline Entrapment efficiency & $100 \%$ & $150 \%$ & Minimize \\
Particle size & $1 \mu \mathrm{m}$ & $5 \mu \mathrm{m}$ & In range \\
Rifampicin release in pH 7.4 & $0 \%$ & $30 \%$ & In range \\
Rifampicin release in pH 4.5 & $30 \%$ & $50 \%$ & In range \\
\hline
\end{tabular}

\section{Characterization of the optimal formula}

The predicted results obtained from the software were then characterized for its entrapment efficiency, particle size, rifampicin release at $\mathrm{pH} 7.4$ and $\mathrm{pH} 4.5$. The results were depicted in Table 6.

Table 6: Characterization results of optimum formula.

\begin{tabular}{|c|c|c|c|c|c|c|c|c|}
\hline \multirow{2}{*}{$\mathbf{F}$} & \multicolumn{2}{|c|}{ Entrapment Efficiency (\%) } & \multicolumn{2}{|c|}{ Particle size $(\mu \mathrm{m})$} & \multicolumn{2}{|c|}{ Rifampicin release pH $7.4(\%)$} & \multicolumn{2}{|c|}{ Rifampicin release pH $4.5(\%)$} \\
\hline & Actual & Predicted & Actual & Predicted & Actual & Predicted & Actual & Predicted \\
\hline FO1 & 108.9 & 107.1 & 1.177 & 1.001 & 14.49 & 17.8 & 37.97 & 32.6 \\
\hline $\mathrm{FO} 2$ & 108.9 & 107.5 & 1.617 & 1.500 & 15.3 & 17.6 & 22.52 & 30.8 \\
\hline FO3 & 109.32 & 110.1 & 2.089 & 1.300 & 26.34 & 17.0 & 21.28 & 30.0 \\
\hline
\end{tabular}

\section{DISCUSSION}

In characterization of functional group analysis, the peak at the $1616.41 \mathrm{~cm}^{-1}$ wave number indicated the ionic interaction between the protonated $-\mathrm{NH}_{3}^{+}$of the amine group $\left(-\mathrm{NH}_{2}\right)$ in chitosan with $-\mathrm{COO}^{-}$dissociated from the carboxylic group $(-\mathrm{COOH})$ in xanthan gum, forming a polyelectrolyte complex (Lankalapalli and Kolapalli, 2009). In the spectrum of CX, there are also functional groups owned by chitosan and gum xanthan. It shows that not all amine groups react with carboxylate groups because in the spectrum of CX there were still carboxylic and amine groups peaks in the spectrum of CX (Varshosaz et al., 2015).

Preparation of rifampicin inhalation powder with spray dryer made based on three different parameters in each formulation, i.e., the concentration of CX solution, inlet temperature, and ratio RIF:CX. The concentration of the solution will affect the viscosity of the liquid, then change on the droplet size after spraying. It also may affect the powder yield and particle size response. The rifampicin ratio with $\mathrm{CX}$ will affect the formation of films of polymer against the drug so that the factor will affect the response of rifampicin release, the entrapment efficiency, and the particle size in the rifampicin dry powder (Paudel, 2013).

The average particle size values obtained were not entirely within the required particle size range for the inhalation powder (1 $\mu \mathrm{m}-5 \mu \mathrm{m})$ (Hickey, 2004). It may be due to the broad particle size distribution of powders, which was indicated by its relatively large polydispersity index (PDI) (data not shown). The higher the value of PDI, the more heterogeneous the powder (Avadi, 2010). Based on the particle size results, the CX concentration in solution and ratio of RIF:CX affects the viscosity of the spray dried liquid, and the viscosity affects the size of the powder particles (Paudel, 2013). The viscosity affected the droplet size after spraying on the spray dryer, thus affecting the size of the resulted particles. The effect of RIF:CX ratio, CX concentration and inlet temperature to particle size of rifampicin DPI are depicted in Figure 5.

All formulas showed entrapment efficiency value higher than $100 \%$; it might be due to properties of sprayed solution. The CX solution was slightly insoluble; thus it poorly flows into collecting tube of the spray dryer. The Buchi manual explained this condition might cause some excipient was left on the tube and unable to coat the API (rifampicin) perfectly (Büchi, 2015). Furthermore, coherently with Paudel et al., our results also showed that entrapment efficiency in inhalation powder was influenced by the drug-polymer ratio (Table 3) (Paudel, 2013). The higher CX-rifampicin ratio, the higher entrapment efficiency value of the powder. Response surface of entrapment efficiency toward RIF:CX ratio and inlet temperature in various $\mathrm{CX}$ concentration can be observed in Figure 4.

Our results showed that rifampicin was released higher from the DPI in the medium $\mathrm{pH} 4.5$ than in the medium $\mathrm{pH} 7.4$ (Figure 2 and Figure 3). It was due to the higher solubility of 
chitosan in acidic medium, thus coating layer of CX was dissolved better in medium $\mathrm{pH} 4.5$ and released more rifampicin from the powder. Furthermore, our results also showed that rifampicin released was strongly influenced by Rif-CX (drug-polymer) ratio (Table 3). Higher polymer concentration increased coating layer of the powder, thus sustained drug release from the powder, both in medium $\mathrm{pH} 4.5$ and $\mathrm{pH} 7.4$ (Berger et al., 2004). Response surface of rifampicin release in medium $\mathrm{pH} 7.4$ and $\mathrm{pH} 4.5$ toward $\mathrm{RIF}: \mathrm{CX}$ ratio and inlet temperature in various $\mathrm{CX}$ concentration are presented in Figure 6 \& Figure 7, respectively.

Based on the characterization results of the fourteen formulas, the optimization of dry powder formulas was carried out with response surface methodology. The responses obtained from each formula were later incorporated into the experimental design. According to the obtained optimization, the response surfaces of the entrapment efficiency and the rifampicin release in medium $\mathrm{pH} 4.5$ as well as $\mathrm{pH} 7.4$ had the correlation values more than \pm 0.5 to the RIF:CX ratio. It shows that the RIF:CX ratio gives the dominant influence over the three responses. The correlation value of 0.631 was obtained on the response of the absorption efficiency to the RIF:CX ratio, it showed the positive correlation value that was the higher the excipient ratio to rifampicin, the higher the entrapment efficiency obtained.

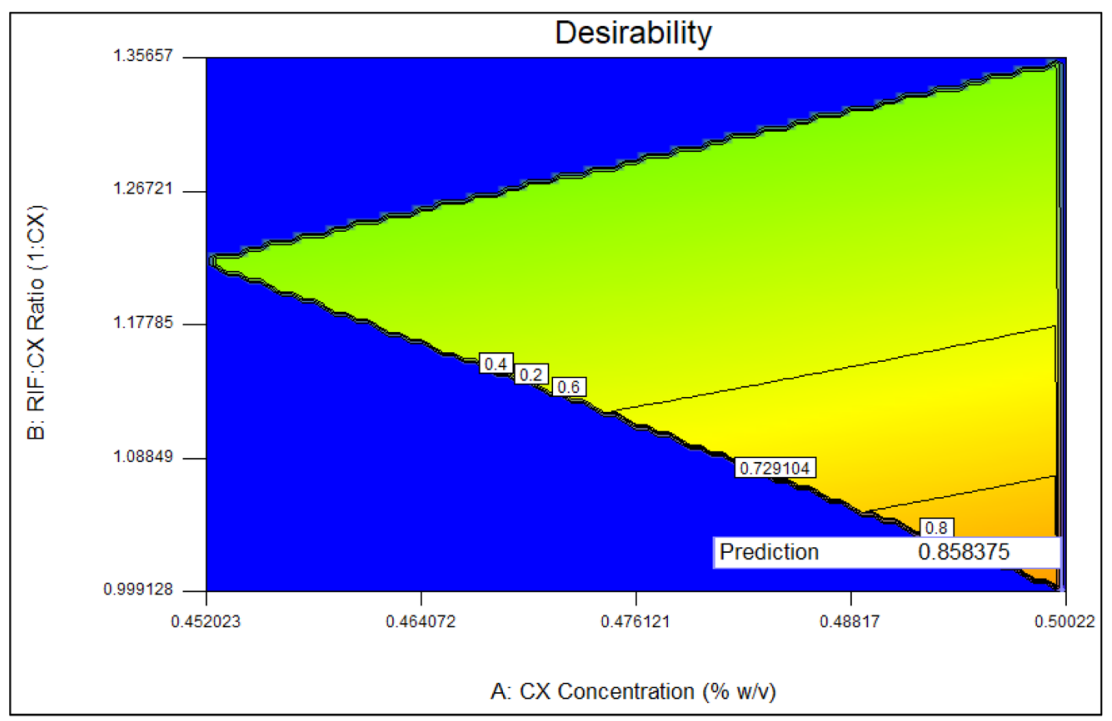

Fig. 9: Desirability graphic of optimization.

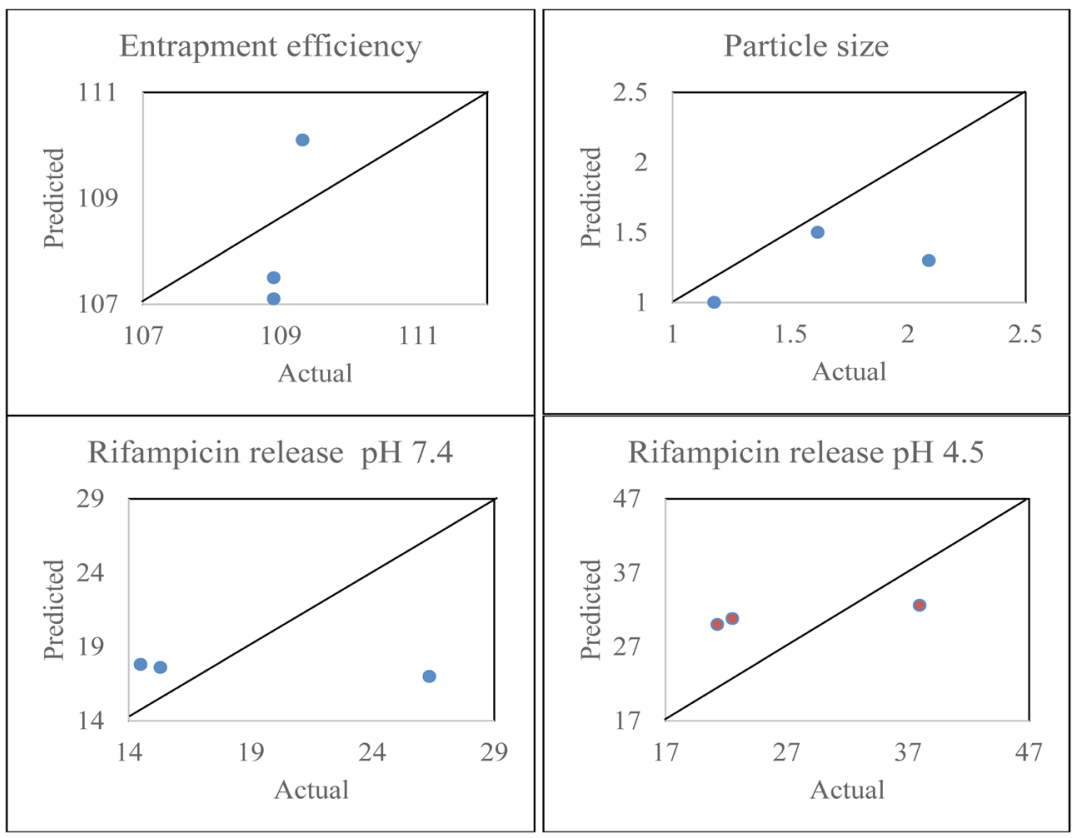

Fig. 10: Actual vs predicted of the optimum formula. 
In response to the release of rifampicin, a negative correlation was obtained. The value of -0.664 was obtained in the response of rifampicin release in the $\mathrm{pH}$ medium of 7.4 and the value of -0.557 was obtained in the response of rifampicin release in the $\mathrm{pH} 4.5$ medium to the RIF:CX ratio factor. It can be interpreted that the greater the ratio of excipients to rifampicin, the less the number of rifampicin being released. In the particle size response, the correlation value for the three input variables was $<0.5$, indicating that the input variables only have small effect on the particle size. The correlation value between the particle size and the concentration of CX solution and the RIF:CX ratio is 0.233 and 0.262 , so it can be interpreted that the concentration factor of CX and RIF:CX gave little influence on the particle size. The higher the concentration of CX solution and the RIF:CX ratio, the bigger particle size obtained.

The optimization result was obtained at the CX concentration $0.5 \%$, inlet temperature $143^{\circ} \mathrm{C}$, and the ratio of RIF:CX 1:1, with the response value of entrapment efficiency $107,1 \%$, particle size $1,001 \mu \mathrm{m}$, rifampicin release in $\mathrm{pH} 7.4$ $17.8 \%$ and $\mathrm{pH} 4.532 .6 \%$. At that point, the desirability value was 0.86 (Figure 8 and Figure 9) thus the actual response-obtained from the input factor at the optimum point may not be the same as predicted.

Table 6 and Figure 10 showed that the predicted response value does not match perfectly to the actual response value. It was due to the desirability value is only 0.86 ; thus the actual result was slightly different to the prediction. However, with high prediction value, the obtained-response was close to the prediction.

\section{CONCLUSION}

The RSM successfully designed an optimum formula of Rifampicin DPI at the point of $0.5 \% \mathrm{CX}$ concentration, RIF:CX ratio $1: 1$, and inlet temperature at $143^{\circ} \mathrm{C}$, which produced rifampicin DPI with EE of $108.9 \%$, particle size of $1.177 \mu \mathrm{m}$, and the release of rifampicin of $14.49 \%$ at $\mathrm{pH} 7.4$ and $37.97 \%$ at $\mathrm{pH} 4.5$.

\section{ACKNOWLEDGEMENT}

The authors gratefully acknowledge to Directorate of Research and Community Engagements of Universitas Indonesia for financial support.

\section{CONFLICT OF INTERESTS}

There are no conflicts of interest.

\section{REFERENCES}

Argin-Soysal S, Kofinas P, Lo YM. Effect of complexation conditions on xanthan-chitosan polyelectrolyte complex gels. Food Hydrocolloids, 2009; 23; 202-209.

Avadi MR, Assal MS, Nasser M, Saideh A, Fatemeh, A, Rassoul D, Morteza R. Preparation and characterization of insulin nanoparticles using chitosan and Arabic gum with ionic gelation method. Nanomedicine: Nanotechnology, Biology, and Medicine, 2010; 6, 58-63.

Berger J, Reist M, Mayer JM, Felt O, Gurney R. Structure and Interaction in Chitosan Hydrogels Formed by Complexation or Aggregation for Biomedical Application. European Journal of Pharmaceutics and Biopharmaceutics, 2004; 57; 35-52.

Bolton S, Bon C. 2010. Pharmaceutical Statistics: Practical and Clinical Applications. 5th Ed. CRC Press Taylor and Francis Group.

British Pharmacopoeia. 2013. British Pharmacopoeia. London, UK: The Stationery.
Büchi Labortechnik AG. Spray Drying \& Encapsulation Solutions - Particle formation for lab scale. Brochure, No. 11592837 En 15/09 E, 2015; 24.

Chaudhary H, Kohli K, Kumar V. Nano-transfersomes as a novel carrier for transdermal delivery. International Journal of Pharmaceutics, 2013; 454(1); 367-380.

Esteban C, and Severian D. Chitosan-Xanthan Based Polyionic Hydrogels for Stabilization and Controlled Release of Vitamins. United State Patent, 2005; 424/400.

FDA. 2016. Adverse Effects Rifampicin. [ONLINE] Available at http://www.micromedexsolutions.com. [Accessed 27 November 2016].

Hamman JH. Chitosan-based polyelectrolyte complexes as potential carrier materials in drug delivery systems. Marine Drugs, 2010; 8(4), 1305-1322.

Hickey AJ, 2004. Pharmaceutical Inhalation Aerosol Technology. $2^{\text {nd }}$ Ed. New York, USA: Marcel Dekker, Inc.

Hussain, Ajaz S, Yu, Xuaqiang, Johnson, Robert D. Application of Neutral Computing in Pharmaceutical Product Development Pharmaceutical Research, 1991; Vol 8. Plenum Publishing be Corporation.

Keshani S, Daud WR, Nourouzi MM, Namvar F, Ghasemi M. Spray drying: An overview on wall deposition, process and modeling. Journal of Food Engineering, 2015; 146; 152-162.

Lankalapalli S, and Kolapalli VRM. Polyelectrolyte Complexes: A review of their Applicability in Drug Delivery Technology. Indian Journal of Pharmaceutical Sciences, 2009; 71(5); 481-487.

Myers HR, Montgomery CD, Anderson-Cook MC. 2016 Response Surface Methodology: Process and Product Optimization Using Designed Experiments. $4^{\text {th }}$ Ed. Hoboken, New Jersey: John Wiley \& Sons, Inc.

Park JH, Jin HE, Kim DD, Chung SJ, Shim WS, Shim CK. Chitosan microspheres as an alveolar macrophage delivery system of ofloxacin via pulmonary inhalation. Int Journal of Pharm, 2013; 441(1-2); $562-569$.

Patel B, Gupta N, Ahsan F. Particle engineering to enhance or lessen particle uptake by alveolar macrophages and to influence the therapeutic outcome. European Journal of Pharmaceutics and Biopharmaceutics, 2015; 89; 163-174.

Paudel A, Worku ZA, Meeus J, Guns S, Van Den Mooter G. Manufacturing of solid dispersions of poorly water-soluble drugs by spray drying: Formulation and process considerations. International Journal of Pharmaceutics, 2013; 453(1); 253-284.

Son YJ, and McConville JT. A new respirable form of rifampicin. European Journal of Pharmaceutics and Biopharmaceutics, 2011; 78(3); 366-376.

Stefaniak AB, Virji MA, Day GA. Dissolution of beryllium in artificial lung alveolar macrophage phagolysosomal fluid. Chemosphere, 2011; 83(8); 1181-1187.

Putri KSS, Sulistomo B, \& Surini S. Kompleks Polielektrolit Kitosan-Xanthan sebagai Matriks Sediaan Mukoadhesif. Pharmaceutical Sciences And Research (PSR), 2017; 4(1); 1-12. doi:10.7454/psr.v4i1.3631.

Varshosaz J, Tavakoli N, Moghaddam F, Ghassami E. Polyelectrolyte complexes of chitosan for production of sustained release tablets of bupropion $\mathrm{HCl}$. Farmacia, 2015; 63; 1 .

Zhou Q, Leung SSY, Tang P, Parumasivam T, Loh ZH, Chan HK. Inhaled formulations and pulmonary drug delivery systems for respiratory infections. Advanced Drug Delivery Reviews, 2014; 85; 83-99.

How to cite this article:

Surini S, Providya R, Putri KSS. Formula Optimization of Rifampicin Dry Powder Inhalation with Chitosan-Xanthan Carrier Using Response Surface Methodology. J App Pharm Sci, 2019; 9(01): 033-041. 